\title{
A Relevância da Carta de Leibniz PaRa Casati
}

\author{
[The ReleVAnCE of Leibniz's LetTer to CASATI]
}

\author{
Arthur Leandro da Silva Marinho * \\ Universidade Federal da Paraíba, Brasil
}

Resumo: Neste artigo discuto a problemática da carta de 1689, de Leibniz ao Ludovico Casati. Esta carta da fase intermediária de Leibniz, Leibniz argumenta a possibilidade de que as propriedades extrínsecas, bem como, as propriedades intrínsecas não possam distinguir coisas completamente semelhantes. Para Leibniz a existência de coisas indiscerníveis é um absurdo, tendo em vista que o intelecto infinito acompanha a multiplicidade de todas as coisas criadas. Logo, todas as coisas devem ser variadas e distintas, mesmo quando não for possível distinguir as coisas por suas propriedades intrínsecas e extrínsecas. Deste modo, analiso a carta com intuito de compreender a argumentação de Leibniz a Casati, assim como, delimitar o Princípio da identidade dos indiscerníveis, como princípio de distinção. Na argumentação a Casati que o melhor mundo possível é guiado por uma razão que estabelece que as coisas são distintas. Ao fim, disponibilizo uma tradução em língua portuguesa desta carta.

Palavras-Chave: Leibniz, Casati, Princípio da identidade dos indiscerníveis, intelecto infinito.
Abstract: In this article I discuss the problematic of the letter of 1689, from Leibniz to Ludovico Casati. This letter from Leibniz's intermediate phase, Leibniz argues the possibility that extrinsic properties as well as intrinsic properties can not distinguish completely similar things. For Leibniz the existence of indiscernible things is absurd, since the infinite intellect accompanies the multiplicity of all created things. Therefore, all things must be varied and distinct, even when it is not possible to distinguish things by their intrinsic and extrinsic properties. In this way, I analyze the letter with the intuition of understanding Leibniz's argument to Casati, as well as delimiting the Principle of the identity of the indiscernibles, as a principle of distinction. In arguing to Casati that the best possible world is guided by a reason that establishes that things are different. At the end, I provide a translation in Portuguese of this letter.

Keywords: Leibniz, Casati, Principle of the identity of the indiscernibles, infinite intellect.

\section{INTRODUÇÃO}

$\mathrm{D}$ estaca-se, nesse artigo, a carta de Leibniz para o matemático e físico Ludovico Casati, que foi escrita aproximadamente no ano de 1689, trata-se de um texto impregnado das ideias do jovem Leibniz. Sem dúvidas, é um curto documento que passa despercebido, porém é importantíssimo para que seja compreendido o Princípio da Identidade dos Indiscerníveis de Leibniz dentro do seu

* Programa Integrado de Doutorado em Filosofia - PIDIF Universidade Federal da Paraiba.E-mail: arthurlsmarinho@hotmail.com 
sistema filosófico. Um problema dentro deste sistema filosófico implica que seria um sistema mal fundado, portanto o Princípio da Identidade é um princípio explicativo que elimina as brechas de ineficiência do sistema. A existência de indiscerníveis, ou melhor, entes completamente iguais são inconcebíveis para Leibniz. Estes entes indiscerníveis na natureza é uma impossibilidade para que este mundo seja o mais variado, mais rico e harmônico possível. Contra o argumento de que existam entes completamente indiscerníveis na carta a Casati o tema central desta carta é a distinção destes entes. Talvez seja um problema epistemológico, mas antes de tudo é uma questão de distinção empírica. Deste modo, decidimos traduzir a carta para melhor compreender o argumento de Leibniz sobre a distinção. Veremos na carta que Leibniz argumenta que não existem diferenças puramente extrínsecas ao ente, ou melhor, não existem coisas que podem ser distinguidas unicamente por meio daquilo que é extrínseca a elas.

A importância desta carta está em mostrar que Leibniz coloca a Identidade de Indiscerníveis como um princípio de diferença numérica ou distinção, daí nossa desconfiança que a existência de indiscerníveis é um problema epistemológico. Sendo assim, o Princípio exerce um papel fundamental para este sistema filosófico. Então, uma vez que ele também viu a Identidade de Indiscerníveis como um princípio de individuação, no sentido de um princípio de diferença numérica ou distinção, podemos pressupor que seu princípio seja central já em escritos que antecedem a sua maturidade. Devemos ter em vista que os textos mais conhecidos da sua maturidade fazem alusão ao princípio da identidade dos indiscerníveis, por esta razão reconhecer este princípio em escritos da sua juventude, como esta carta a Casati, é como trilhar o caminho que o princípio percorreu.

\section{A carta a Casati}

Ao analisar a carta de Leibniz dirigida ao Padre Casati (A II II 287-8) fazemos o seguinte questionamento: 1. Qual o argumento de Leibniz nesta carta? 2. O que torna esta correspondência deferente? Primeiramente, para responder estas questões apontamos que o argumento de Leibniz considera a concepção de que há muitos objetos no mundo, com exceção de duas esferas perfeitamente semelhantes, que não tenham sido aniquiladas. Como veremos a seguir, esta é uma diferença significativa. Além disso, não há dúvidas que Leibniz tinha boas relações com Roma chegando, inclusive, a ser convidado a exercer o oficio de bibliotecário de Roma, que recusa.

A primeira edição da carta encontra-se publicada no Archiv für Geschichte der Philosophie. Acreditamos que a intencionalidade na argumentação de Leibniz a Casati seja indicar por meio da aniquilação da substância, a concepção de um mundo possível, em que fosse plausível imaginar que neste mundo sempre existiram apenas duas esferas perfeitamente semelhantes.

De acordo com esta interpretação, quando Leibniz fala da aniquilação, ele está levando Casati a aniquilar mentalmente todos os outros objetos, exceto duas esferas perfeitamente semelhantes para que ele possa conceber o mundo como Leibniz pretendia na argumentação. Mas, o que está em destaque é o fato de um mundo que sempre houve apenas duas esferas perfeitamente semelhantes, ou seja, Leibniz não descreve um mundo que fosse criado por Deus. Leibniz descreve um mundo em que houvesse apenas duas esferas perfeitamente semelhantes. Para esclarecer a 
interpretação de aniquilação para Leibniz, fazemos uma analogia com sua interpretação de aniquilação na Monadologia, que por ser um texto da sua maturidade, é fundamental para se entender as nuances da aniquilação. Vejamos:

"Dele infiro, entre outras consequências, que não há na natureza dois seres reais absolutos que sejam indiscerníveis, porque, se existissem, Deus e a natureza agiriam sem razão, tratando a um de outro jeito que a outro. Assim, pois, Deus não produz duas porções de matéria perfeitamente iguais e semelhantes". (LEIBNIZ, 1974, p.432).

Ambos os argumentos usam Deus, que é um ser com uma vontade racional, que escolhe o melhor e mais variado possível, por isso, que não seria capaz de escolher um mundo contendo indiscerníveis. Deus não age sem razão, se o mundo não é o mais variado e harmônico possível, logo, seria contra a razão divina que escolhe o mais variado, que é o mais perfeito. Na carta a Casati, Deus aparece como um ser com um intelecto infinito que não seria capaz de distinguir as coisas indiscerníveis. De modo nenhum o argumento de Leibniz questiona a inteligibilidade. Também é implausível que Leibniz acreditasse como consistentes mundos que houvesse coisas indiscerníveis. Sendo assim, o argumento da carta a Casati tenta estabelecer que a existência de mundos ou indivíduos indiscerníveis é um absurdo.

Além disso, é importante destacar que o argumento não é um argumento epistemológico. Podemos apontar que Leibniz não está argumentando a Casati que é possível alguma distinção entre as coisas indiscerníveis porque Deus distingue ou não as coisas, a questão levantada por Leibniz é, se há coisas distintas que nem mesmo Deus poderia distinguir. Acreditamos que a carta antes de enfraquecer o argumento divino, aponta o poder infinito de Deus que é capaz de distinguir todas as coisas, por sua vontade que escolhe o mais variado, por sua razão que instaura a harmonia préestabelecida entre todas as coisas.

Qual é o argumento de Leibniz para o Princípio de Identidade dos Indiscerníveis nesta carta a Casati? Esta é a forma como reconstruímos argumento: Leibniz parte do pressuposto de que, se todas as coisas são aniquiladas e, como consequência, pudemos apenas identificar a existência de duas coisas perfeitamente semelhantes no espaço. Partindo deste pressuposto, qual seria o princípio da distinção? Explicamos que este princípio de distinção não poderia ser na coisa em si, pois seriam completamente semelhantes. Tampouco em qualquer coisa externa, pois não haveria como entendê-las em suas relações com outras, tendo em vista que todas as coisas tenham sido aniquiladas e, por isso, elas não poderiam ser distinguidas no espaço e tempo. Como sabemos, o posicionamento de Leibniz é apontar que as coisas estão em relação, são estas relações entre as coisas que constituem o espaço e o tempo, não admitindo o espaço absoluto nem o relativo, como Newton apontava nos Princípios Matemáticos. $\mathrm{O}$ problema que Leibniz argumenta é: 1. As propriedades intrínsecas não podem distinguir os entes completamente idênticos; 2. As características extrínsecas, tampouco podem distinguir estes entes, pois não há como reconhecê-las por meio de suas cadeias de relações. Deste modo, nem Deus poderia distinguir estes entes indiscerníveis. Leibniz argumenta que tal suposição seja uma hipótese absurda. Mas, na realidade, o que ele quer reafirmar a Casati é que há uma diferença entre as coisas quando analisadas, em que as características de cada coisa sejam distinguidas. Consequente, não é possível que existam tais coisas completamente semelhantes, principalmente para o intelecto divino 
que acompanha a criação divina, pois o intelecto de Deus é infinito.

O fato é que o princípio da distinção utilizado na Carta a Casati não são as propriedades intrínsecas. É importante fazer este destaque porque nos textos da sua juventude Leibniz apontava que o princípio da indistinção seria um princípio da distinção numérica e, portanto, intrínseco. Nesta carta ele argumenta que o princípio da distinção não está na coisa internamente e nem extrinsecamente, pois elas não fazem relação com quaisquer coisas porque tudo foi aniquilado. Em um mundo que um determinado momento, tudo menos duas esferas perfeitamente semelhantes foram aniquiladas, não há outras entidades a que essas esferas semelhantes estejam relacionadas naquele momento da aniquilação.

Por sua vez, podemos considerarmos a situação em que as únicas coisas existentes foram sempre dois indiscerníveis e que em nenhum momento no tempo tenha existido outros objetos que esses dois completamente semelhantes. Mas esta não é uma situação que Leibniz consideraria uma absurda, outros teóricos mais contemporâneos irão refinar essa situação. E não é a intencionalidade do argumento de Leibniz apontar nesta carta que as únicas coisas existentes tenham sido sempre dois indiscerníveis. No argumento, Leibniz está considerando a existência de dois entes completamente semelhantes como consequência da aniquilação de todas as coisas existentes.

Além disso, as duas esferas restantes podem ser distinguidas através de suas narrativas espaços-temporais. E se, porventura, no tempo de uma dessas duas esferas não fosse possível distinguir uma da outra, então Deus, que tudo sabe, teria conhecimento dos diferentes movimentos das esferas e suas diferentes relações espaciais para coisas completamente semelhantes. E, mesmo sendo Deus, o agente da aniquilação de todas as coisas e da existência destes entes completamente indiscerníveis, mesmo assim Deus saberia e das suas respectivas e diferentes histórias, e usaria essas histórias para distingui-las. De fato, se o intelecto de Deus é infinito, não parece ser nenhum impedimento para que Deus distinga as esferas através de suas histórias espaços-temporais.

Acreditamos que distinguir as esferas através de suas histórias é distingui-las através de outros objetos, inclusive, em suas relações, estados e posições. Isso significa que as substâncias com diferentes histórias são qualitativamente diferentes, Deus sabendo de tudo, pode seguir as esferas através do tempo, de modo que quando ele aniquilou todos os outros objetos eles ainda têm condições para distingui-las. Observemos que distinguir as esferas através de suas histórias é distingui-los através de outros objetos, mesmo que sejam apenas objetos pertencentes ao passado.

Temos evidência e acreditamos que na concepção de Leibniz, distinguir as esferas através de suas histórias seria distingui-los através de sua relação com outros objetos. Pois, de acordo com Leibniz nas suas Correspondências com Clarke, o tempo é a ordem dos corpos de acordo com sua posição sucessiva:

Dizem que o espaço não depende da situação dos corpos. Eu respondo que é verdade que ele não depende do ponto de uma tal ou tal situação entre os corpos; mas é essa ordem que faz com que os corpos sejam situáveis, e pelo qual eles organizam uma situação entre eles por existentes juntos, como o tempo é essa ordem por referência à sua posição sucessiva. (GP VII 376, tradução nossa)

Aqui, Leibniz aponta que o espaço e, consequentemente, o tempo não dependem dos corpos. Porém, o espaço e o tempo são fundados a partir da relação existente entre 
as coisas. E, por sua vez, as coisas são situáveis no espaço e no tempo. Mas na carta a Casati, essa ordem do espaço e do tempo não estabelece uma relação que distingue bem as coisas. Ou seja, através da relação situável entre as coisas, uma não pode ser distinguida a partir de cada uma das outras, tendo em vista que não são situáveis. Isto sugere que, quando há ordem, consequentemente, há uma relação entre as entidades. Portanto, deve haver algo no passado com que as coisas presentes estão relacionadas no tempo, mesmo quando todas as coisas são aniquiladas.

Assim, qualquer que seja a significação de aniquilação, não implica que as coisas aniquiladas deixarão de existir. Mas, em qualquer caso, se é isso que Leibniz quis dizer, o problema reside no fato de apenas coisas indiscerníveis permaneçam após tudo o que foi aniquilado, pois o princípio de distinção em outros objetos não seria suficiente para estabelecer uma distinção em si entre coisas completamente semelhantes, mas Leibniz acredita que eles diferem em virtude de como eles são, bem como, em suas relações a outras entidades.

Além disso, como Deus é capaz de acompanhar todas as coisas possíveis pelo seu intelecto infinito, onde ele não acompanha simplesmente, mas estas coisas estão na compreensão infinita divina e, por isso, as distingue. A compreensão da infinidade de intelecto de Deus é uma premissa que devemos aceitar no argumento de Leibniz.

Leibniz assume, nesta carta a Casati, que o intelecto infinito deve ser capaz de distinguir as coisas completamente semelhantes, ou melhor, as coisas distinguidas pelo intelecto divino.

Assim, para este argumento ser eficaz, Leibniz justifica as razões para que não seja possível que existam as esferas completamente semelhantes, elas são distintas porque são distinguidas por um ser com um intelecto infinito. Esta sustentação argumentativa pode ter sua origem a partir do princípio da razão suficiente na carta a Casati. E mesmo que Leibniz não trate deste princípio explicitamente, é aceitável que este intelecto infinito seja o princípio da razão suficiente. Portanto, há sempre uma razão suficiente para que as coisas sejam distintas. Consequentemente, há sempre um princípio de distinção entre coisas completamente semelhantes, pois pela razão são distinguíveis, e assim, sempre é possível distinguir estas coisas, ao menos, para um intelecto infinito.

Sendo assim, há uma razão suficiente para que todas as duas coisas semelhantes sejam distintas, por isso, não poderia haver duas coisas distintas que não fossem distinguíveis por um intelecto infinito. Sabendo que este intelecto infinito saberia a razão pela qual estas coisas são separadas, então este intelecto estaria numa posição que ultrapasse o espaço e o tempo para distingui-las. E Leibniz reconhece que deve haver sempre uma razão suficiente para que as coisas semelhantes sejam distinguidas. A ideia de que um intelecto infinito deve ser capaz de distinguir estas coisas semelhantes é uma demonstração da força do princípio da identidade dos indiscerníveis, mesmo que ele não especifique o princípio. Por fim, não é possível que Deus aniquile tudo e deixa apenas dois objetos perfeitamente semelhantes. Por tudo o que foi dito não poderia terem sido esferas perfeitamente semelhantes, sabendo que existem outros objetos que em suas diferentes relações estabelecem a distinguibilidade deles e que nem todas estas outras coisas nunca foram aniquiladas. O fato é que nesta carta, Leibniz cria a problemática de que, uma vez que Deus pode aniquilar quaisquer criaturas ele poderia criar uma situação em que há os indiscerníveis. Sem dúvidas, esta é uma situação 
impossível, tendo em vista que o mais variado, mais perfeito e harmônico mundo contenha unicamente as coisas indiscerníveis existentes, mas essa hipótese seria um absurdo ao intelecto infinito divino.

Deus deve ser capaz de aniquilar quaisquer coisas que lhe interessa, tendo em vista que ele é onipotente, e sendo o melhor possível rastreia sua criação. Logo, Deus não poderia criar uma situação que argumenta na Carta a Casati, pois é uma situação que jamais seria possível em quaisquer mundos possíveis leibnizianos. Logo, a existência de indiscerníveis no mundo leibniziano é uma impossibilidade metafísica.

Por fim, é evidente que Leibniz pretende estabelecer o Princípio da Identidade de Indiscerníveis como necessário. Embora no início da carta Leibniz diz que "nunca duas coisas diferem entre si, que eles podem ser distinguidos não apenas por causa extrínseca, mas também por tudo que há neles (A II II 288)”, na verdade, ele pretende aponta que há uma razão para que sejam distintas. Além disso, Leibniz afirma que "não pode haver dois ovos perfeitamente semelhantes que nenhuma diferença neles possa ser observada, se eles foram atentamente examinados ou totalmente inspecionados" (A II II 288). Sem dúvidas, considerar a violação do Princípio da identidade dos indiscerníveis seria um absurdo. Isto sugere profundamente que ele pensou que o princípio é necessário. Por isso, que ele vai confirmar e comprovar sua visão na concepção de Aquino. Este trata de inteligências que não podem ser completamente semelhantes. E é ancorado na concepção de Aquino que ele aponta que "não pode haver duas inteligências separadas que são perfeitamente semelhantes uns aos outros" (A II II 289). Deste modo, é absurdo que há coisas distintas que não possam ser distinguidos por um intelecto infinito. É plausível que Leibniz tenha pensado que também seja um absurdo que sejam possíveis coisas que não possam ser distinguidos por um intelecto infinito. Isso sugere que ele pode ter sido inclinado a atribuir forte necessidade de a Identidade de Indiscernível na carta a Casati. Logo, não há coisas possíveis que são perfeitamente semelhantes. Mesmo levantando a hipótese de que todas as coisas aniquiladas partilham o mesmo espaço, não faz sentido que pertencem ao mesmo mundo possível somente duas coisas que são completamente semelhantes.

\section{Conclusão}

Como pudemos perceber, o argumento na carta começa pela afirmação de que não há determinação que seja puramente extrínseca, ou seja, deve haver uma disposição no próprio ente que o distinga dos demais, por mais semelhantes que sejam. Contudo, Leibniz argumenta uma possível relação entre as propriedades intrínsecas e extrínsecas para que as coisas distinguíveis. As coisas são distinguidas por suas propriedades externas, como também, por suas propriedades internas. Isto, nos faz lembrar que,

...as mônadas precisam ter algumas qualidades, pois, caso contrário, nem mesmo seriam entes. Se as substâncias simples em nada diferissem pelas suas qualidades, não haveria meio de se aperceber qualquer modificação nas coisas, pois o que está no composto não pode vir senão de ingredientes simples, e as mônadas, não tendo qualidades, seriam indistinguíveis umas das outras, visto não diferirem também e quantidade; e, por conseguinte, admitido o pleno, cada lugar receberia sempre, em movimento, só o equivalente do que antes contivera, e um estado de coisas seria, indiscernível de outro (LEIBNIZ, 1974, p. 63). 
Não temos dúvidas de que neste exceto da Monadologia, texto da maturidade do Leibniz, a formulação do Princípio já estava formulado de certa forma na carta a Casati. Na Monadologia, as mônadas têm qualidades que não são unicamente extrínsecas. E é porque as mônadas, que são substâncias simples, possuem qualidades que as distinguem de todas as outras. As mônadas não podendo ser distinguíveis por suas propriedades são indiscerníveis, ou melhor, uma vez que intrinsecamente tivessem as mesmas qualidades, consequentemente as propriedades extrínsecas seriam insuficientes para distinguir o ente. Neste sentido, na carta a Casati, Leibniz argumenta a partir de caso empírico. Ele parte do exemplo de dois ovos que depositados numa cesta seja impossível descobrir sua causa. No entanto, ele aponta que deve haver um princípio de distinção numa diversidade de entes que possam ser semelhantes. Além disso, Leibniz chega a propor um espaço imaginário em que mesmo todas as coisas estejam aniquiladas permanecendo duas esferas complemente semelhantes deve haver algo que acompanhe o ente, e, conheça sua causa, o distingue dos demais entes. $\mathrm{O}$ argumento de Leibniz, aqui, é de que todas as coisas estejam aniquiladas. Havendo dois entes semelhantes. Se o problema fosse simplesmente epistemológico, seria um simples problema da mente de quem concebe o problema. No entanto, Leibniz assegura que os entes devem diferir por suas características e suas relações estabelecidas pelo intelecto infinito.

Ad R.P. [Casati] Lectorem Theologiae in Collegio Clementino urbis Romae.

Quemadmodum optime ostensum est, nullam esse determinationem purê extrinsecam, hoc est nullam rem ad novam aliquam actionem determinari nisi excitetur nova aliqua ad agendum dispositio in ipsa; ita semper arbitratus sum nullam dari diffrentiam pure extrinsecam, hoc est (ne quis in verbis cavilletur) nunquam duas res inter se differre, quin discerni possint non tantum per extrinseca, sed etiam per ea quae sunt in ipsis. Res exemplo intelligetur clarius. Si duo dentur ova $\mathrm{A}$ et $\mathrm{B}$ posita in cista $\mathrm{CD}$, sitque $\mathrm{A}$ ovum gallinae albae et $\mathrm{B}$ nigrae, eaque Ova sint admodum similia inter se et equalia, tunc utique licet per se discerni facile et primo aspectu non possint, poterunt discerni facillime ipso situ in cista, ut si unum A ponatur in loculamento cistae medio, alterum $\mathrm{B}$ in loculamento quod sit angulo vicinum; tunc optime poterunt discerni per differentiam hanc extrinsecam;

Para o Reverendíssimo Padre [Casati], docente de Teologia no Colégio Clementino da cidade de Roma.
Como muito bem é mostrado, não há nenhuma determinação puramente extrínseca, isto é, não há nenhuma nova ação se não for excitada por uma nova disposição dela mesma; assim sempre suponho que dada à diferença puramente extrínseca, isto é (para que nenhum astucioso diga que), nunca duas coisas diferem entre si, que eles podem ser distinguidos não apenas por causa extrínseca, mas também por tudo que há nelas. Isto pode ser compreendido de forma mais clara por meio de um exemplo. Se houvesse dois ovos A e B depositados em uma cesta $\mathrm{CD}$, ovo A foi deixado por galinha branca e B por galinha negra, e os ovos sejam inteiramente semelhantes e iguais, em seguida, certamente mesmo se eles não possam ser distinguidos por si facilmente à primeira vista, eles podem ser mais facilmente distinguidos através de sua posição na cesta, e se um A foi colocado no meio do cesto, e o outro B, foi colocado no ângulo próximo; então você vai muito bem discernir a diferença extrínseca; nesse caso, eles são mais eficazmente distinguidos por esta diferença extrínseca;

Dico tamen hanc differentiam extrinsecam duorum ovorum etsi nobis serviat, nihil ominus in re non sufficere, sed supponere 
differentiam aliquam intrinsecam in ipsis ovis, adeoque non posse dari duo ova tam perfecte similia, ut nullum in iis discrimen notari possit, si attente considerentur aut perfecte 34 perspicerentur.

Nimirum si diversa sunt $A$ et $B$ utique habebunt in se diversitatem, seu principium discernendi, in se inquam, abstrahendo animum $\mathrm{ab}$ externis. Nam fingamus externa omnia annihilari et duos globos materiales (quos nunc ovis substituam) solos superesse in spatio imaginario, tunc dico a nemine quanticunque sit intellectus, nec ab angelo imo ne a Deo quidem istos duos globos perfecte aequales et similes posse discerni. Cum principium discernendi non sit in ipsis (ex hypothesi adversariorum), nec in externis ex hypothesi sublatorum externorum, nec partes spatii imaginarii quibus circumdantur globi queant discerni inter se.

No entanto, digo que, embora essa diferença extrínseca entre dois ovos seja útil para nós, no entanto não é suficiente na realidade, mas pressupõe alguma diferença intrínseca nos próprios ovos, portanto, não pode haver dois ovos tão perfeitamente semelhante que nenhuma diferença possa ser observada nos mesmos, se eles foram atentamente examinado ou totalmente inspecionado.

Certamente, se A e B são diferentes, então, sem dúvida eles terão uma diversidade, ou um princípio de distinção, em si mesmos, sem precisar pensar em objetos externos. Agora suponhamos que todos os objetos externos são aniquilados e que duas esferas materiais (que agora vou substituir por ovos) que permanecem sozinhas no espaço imaginário, então eu digo que, por maior que seja o seu intelecto, nem por um anjo, nem por Deus, podem essas duas esferas perfeitamente iguais e similares serem distinguidas. No caso, o princípio de distinção não seria em si (dada à hipótese dos adversários), ou em objetos externos dada a hipótese da remoção de objetos externos, nem pode as partes imaginárias do espaço que rodeiam as esferas serem distinguidas uma da outra.

Absurdum autem est dari duo diversa, quae ne ab infinito quidem intellectu discerni possint.

Atque haec per experientiam confirmantur, nunquam enim ovum ovo, lac lacti, folium folio, animal animali, et generaliter res rei ita similis reperietur, quin accurata inspectione facta discrimen aliquod notari possit; quod in foliis arborum et graminibus hortorum aliquando inter deambulandum a foemina principe magni ingenii jucunde observatum memini.

Et sane ut a corporibus ad intelligentias transeamus, D. Thomas praeclare notavit, non posse dari duas intelligentias separatas perfecte inter se similes, et licet perfectam similitudinem in corporibus dari posse putarit, hoc tamen ex natura materiae non satis ejus temporibus perspecta natum est. Et fortasse tantum voluit dari corpora quae specie non differant, etsi aliter dissimilia sint.

Mas é absurdo que existam duas coisas distintas, que não possam ser discernidas de fato por um intelecto infinito.

E essas coisas são confirmadas pela experiência, pois nunca serão encontrados dois ovos, ou duas gotas de leite, ou duas folhas, ou dois animais, e em geral duas coisas tão semelhantes que, após uma inspeção precisa, uma diferença não possa ser detectada; que, como me lembro, já foi agradavelmente observado por uma princesa de grande talento, enquanto ela estava numa caminhada, sobre as folhas das árvores e as camadas de grama do jardim.

E, de fato, já que possamos de corpos para inteligências, o que $\mathrm{S}$. Tomás observou claramente, não pode haver duas inteligências separadas que são perfeitamente semelhantes umas as outras, e mesmo que ele pense que não pode haver perfeitamente semelhança nos corpos, isto originou, no entanto, o fato de que, no seu tempo a natureza da matéria não foi suficientemente compreendida. E talvez ele só quisesse que existissem corpos que não diferem 
em espécie, mesmo se eles sejam diferentes de outra forma.

Quod vero ad animas attinet, equidem verum est Humanas Mentes inter se non differre in specie, non tamen hinc inferri debet, eas perfecte similes esse, multa enim quae in specie non differunt, nihilo minus discerni per se posse constat, magnitudine, gradu, variisque proportionibus ut duo homines lineamentis vultus dignoscuntur. Et licet plurimum discriminis in mentibus oriatur ex iis quae corporibus quibus uniuntur accidunt, attamen dicendum est, primo statim infusionis instanti differre animas, nec adeo ullum momentum dari, quo sint perfecte similes. Et certe inter Christi et Judae animas per se spectatas nullum aliquando fuisse discrimen non sine absurditate dici posse videtur. Adeoque tuto sine ullo censurae metu defendere poterimus duas animas perfecte inter se similes nunquam dari, idemque in universum in rebus verum esse. Ex qua jam veritate multa alia momenti maximi, de quibus alias, consequuntur.

$\mathrm{Na}$ verdade, no que diz respeito às almas, é claro que a mente humana não diferem entre si em espécies, no entanto, não deve ser inferida a partir disso que eles são perfeitamente semelhantes, mas para muitos elas não diferem em espécies, como é bem conhecido, podem distinguir-se por si mesmas por sua grandeza, grau, e diferentes relações como dois homens distinguem-se pelas características da face. E mesmo que a maior parte da diferença entre as mentes tenha sua origem nas coisas que acontecem com os organismos com os quais eles estão unidos, no entanto, deve-se dizer que as almas que diferem umas das outras, desde o primeiro momento de sua infusão, e não tenho identificado nenhum momento que eles são perfeitamente semelhantes. E, certamente, é absurdo dizer que em algum momento não houve diferença entre as almas de Cristo e Judas quando são observadas em si mesmas. E assim podemos defender com segurança e sem qualquer medo de críticas de que nunca há duas almas perfeitamente semelhantes, e o mesmo acontece com as coisas em geral. Em conformidade com esta verdade seguem muitas outras coisas de máxima importância, sobre o qual falarei em outra ocasião.

\section{REFERÊNCIAS}

FRANKEL, L. Leibniz's Principle of identity of indiscernibles, Studia Leibnitiana, XIII, 2, PP. 192-211, 1981

HACKING, I. The identity of Indiscernibles, The Journal of Philosophy, 72, 9, pp. 249-256, 1975.

JAUERNIG, A. The modal strength of Leibniz's principle of the identity of Indiscernibles, Oxford Studies in Early Modern Philosophy, IV, pp. 191-225, 2008.

JOSEPH, H. W. B. Lectures on the Philosophy of Leibniz. Oxford: Clarendon Press, 1949.

LEIBNIZ, G. W. Correspondências com Clarke, tradução e notas Carlos Lopes de Mattos. In: Coleção Os pensadores. São Paulo: Abril Cultural, 1974.

LEIBNIZ, G. W. Die Philosophische Schriften, editado por C. I. Gerhardt. Berlin, 1875-90. (Lêse GP, seguido de volume, série e página).

LEIBNIZ, G. W. Discurso de metafísica e outros textos. Apresentação Tessa Moura Lacerda, tradução Marilena Chauí e Alexandre C. Bonilha. São Paulo: Martins Fontes, 2004.

LEIBNIZ, G. W. Meditação sobre o princípio dos indivíduos. Traduzido por Fernando Barreto Gallas. Disponível em: http://www.leibnizbrasil.pro.br/leibniz - traducoes/meditacaosobre-principio-individuos.htm. Visualizado: 12/02/2014, às $12 \mathrm{~h}$.

LEIBNIZ, G. W. Monadologia, tradução Marilena Chauí. In: Coleção Os pensadores. São Paulo: Abril Cultural, 1974.

LEIBNIZ, G. W. Opuscules et fragments inédits de Leibniz, editado por L. Couturat. Paris: Presses Universitaires de France, 1903.

LEIBNIZ, G. W. Sämtliche Schriften und Briefe, editado pela Deutsche Akademie der 
Wissenschaften zu Berlin. Darmstadt, 1923 ff., Leibniz, 1938 ff., Berlim, 1950 ff. (Lêse A, seguido de volume, série e página).

LEIBNIZ, G. W. Ensaios de Teodiceia: sobre a bondade de Deus, a liberdade do homem e a origem do mal. Tradução: William de Siqueira Piaú, Juliana Cecci Silva. São Paulo: Estação Liberdade, 2013. 